\title{
КОНТУРЫ НОВОЙ МИГРАЦИОННОЙ ПОЛИТИКИ СОЕДИНЁННОГО КОРОЛЕВСТВА
}

\begin{abstract}
Аннотация. С 2010 г. правительство Соединённого Королевства проводит политику ужесточения правил въезда и пребывания иностранных граждан. Формирование «неблагоприятной среды» для мигрантов и усиление антимиграционной риторики, адресованной в первую очередь к мобильным гражданам Европейского союза, способствовали победе сторонников выхода из ЕС. Сегодня споры об условиях выхода из Евросоюза совпадают с дискуссиями о будущей миграционной политике, включая правовой статус граждан ЕС в Британии на этапе постбрекзит. Контуры новой политики в сфере миграции пока не яснь, однако политическое руководство даёт понять, что намерено сделать ставку на квалифицированные рабочие кадры из третьих стран.
\end{abstract}

Ключевые слова: Соединённое Королевство, миграчия, «неблагоприятная среда», Евросоюз, брекзит, Содружество наций, Т. Мэй, visa Tier2, иностранная рабочая сила.

\section{«Неблагоприятная среда» для мигрантов}

С 2010 г. Консервативная партия безуспешно пытается сократить приток мигрантов в Британию. Последние 25 лет сальдо миграции в Соединённом Королевстве (разница между количеством въехавших и выехавших) значительно увеличилось. Если в 1991 г. этот показатель не превышал 37 тыс. человек в год, то в 2013 г. он достиг уже 277 тыс., в 2017 г. - 285 тыс., по состоянию на июнь 2018 г. - 273 тыс. $^{1}$ В целом с 1991 по 2017 гг. приток иммигрантов в Британию возрос на 91\% (с 329 тыс. до 644 тыс. в год). К июню 2018 г. в Соединённое Королевство уже въехало 625 тыс. человек.

Ещё в 1948 г. лейбористское правительство приняло Акт о гражданстве, который закрепил статус «гражданина Соединённого Королевства и колоний». Согласно принятому закону, иммигранты из Содружества и колоний получали право проживать в Великобритании и беспрепятственно получать гражданство. В тот же год на знаменитом лайнере «Эмпайр Виндраш» в Соединённое Королевство прибыла первая партия трудовых мигрантов из стран Карибского бассейна. Позже потомков этих переселенцев стали называть «поколение Виндраш».

Массовый приток трудовых мигрантов в Британию завершился в 1971 г. с принятием Иммиграционного Акта, ужесточившего миграционное законодательство. Бо́льшую часть второй половины XX в. показатели въехавших и выехавших были сопоставимы. А в период с 1960 по 1990-е гг. сальдо миграции было даже отрицательным (выехавших британцев было больше, чем иммигрантов в страну).

С присоединением Соединённого Королевства к Единому европейскому рынку динамика миграционных процессов в стране изменилась. В 2004 г. лейбористское правительство одо-

(C) Годованюк Кира Анатольевна - кандидат политических наук, старший научный сотрудник Центра британских исследований ИЕ РАН. Aдрес: 125009, Россия, Москва, ул. Моховая, д. 11, стр. 3. Email: kira.godovanyuk@gmail.com.

DOI: http://dx.doi.org/10.15211/vestnikieran6201812

${ }^{1}$ Migration Statistics. Briefing Paper. House of Commons Library. Number SN06077, 11 December 2018. P. 7. 
брило беспрепятственный доступ к рынку труда гражданам из стран Восточной Европы, которые недавно вступили в Европейский союз, что привело к массовому наплыву рабочей силы.

С годами у населения Британии сформировалось ощущение, что членство в ЕС и иммиграция - взаимосвязанные понятия. Недовольство простых британцев подхватила право-популистская Партия независимости Соединённого Королевства (ПНСК), которая позиционировала себя силой, способной остановить приток мигрантов.

Антимиграционную риторику взяли на вооружение и тори. В 2010 г в манифесте Консервативной партии была зафиксирована задача снизить сальдо миграции до ста тысяч человек в год. К этой цели стремилось и коалиционное правительство тори и либеральных демократов, которое не стремилось закрыть границы для иностранных работников, а сформулировать комплекс мер, направленных на сокращение миграции.

Юридически британский кабинет не мог ограничить доступ граждан ЕС к рынку труда (именно это обстоятельство в какой-то степени и спровоцировало референдум о членстве в Евросоюзе и последующий брекзит). Для многих подданных Соединённого Королевства вынесенный на плебисцит вопрос звучал следующим образом: согласны ли Вы, чтобы рабочие из ЕС продолжали свободно въезжать в страну?

Между тем ужесточение миграционных правил для граждан третьих стран приобрело более завуалированный характер. В 2012 г. Т. Мэй объявила, что ограничительная политика станет эффективнее, если будет создана «неблагоприятная среда» (hostile environment) для нелегальных мигрантов (лиц, нарушивших административные правила въезда и пребывания) ${ }^{1}$.

Фактически в отношении иммигрантов начинала действовать «презумпция виновности»: любой мигрант подозревался в нарушении миграционного законодательства, пока не будет доказано обратное. Миграционные проверки выходили за пределы паспортного контроля на границе и могли проводиться при медицинском обслуживании, оформлении аренды дома или при получении водительского удостоверения.

Юридически «неблагоприятная среда» была зафиксирована в Иммиграционных актах от 2014 и 2016 гг., куда были включены запретительные меры для нарушителей миграционного законодательства, ограничивающие доступ к рынку труда, медицинскому обслуживанию, жилью, образованию и прочее.

Так, согласно Акту от 2014 г. $^{2}$, арендодатели должны были проверять иммиграционный статус жильцов на возможность вносить выплаты в систему здравоохранения. Согласно данным Ассоциации арендодателей Великобритании от ноября 2017 г., 42\% владельцев жилья отказывались сдавать недвижимость лицам, которые не обладают британским паспортом ${ }^{3}$.

Коалиционное правительство приняло меры, направленные на ограничение практически всех миграционных потоков из третьих стран ${ }^{4}$.

Накануне саммита Содружества наций в апреле 2018 г. разразился «скандал Виндраш». Стало известно, что ещё в 2010 г. МВД уничтожило все въездные карточки на прибывших трудовых мигрантов из стран Содружества в период с 1948-1971 гг. ${ }^{5}$ В результате потомки

\footnotetext{
${ }^{1}$ Theresa May interview: «We're going to give illegal migrants a really hostile reception». URL: https://www. telegraph.co.uk/news/uknews/immigration/9291483/Theresa-May-interview-Were-going-to-give-illegal-migrants-a-reallyhostile-reception.html (дата обращения: 15.12.2018).

${ }^{2}$ Immigration Act 2014. URL: https://www.gov.uk/government/collections/immigration-bill (дата обращения: 15.12. 2018).

${ }^{3}$ State Intervention into Renting: Making sense of the impact of policy changes. URL: https://research.rla.org.uk/wpcontent/uploads/state-intervention-into-renting-2017-report.pdf (дата обращения: 15.12.2018).

${ }^{4}$ Immigration and asylum: changes made by the Coalition Government 2010-2015. URL: https://researchbriefings.par liament.uk/ResearchBriefing/Summary/SN05829\#fullreport (дата обращения: 15.12.2018).

${ }^{5}$ Home Office destroyed Windrush landing cards, says ex-staffer. URL: https://www.theguardian.com/uk-news/2018/ Научно-аналитический вестник ИЕ РАН, 2018, №6
} 
переселенцев из бывших колоний лишились юридических оснований проживать в Британии, иметь доступ к здравоохранению, рынку труда и недвижимости, большинству грозила депортация ${ }^{1}$. В ходе скандала также вскрылось, что правительство установило целевые показатели по выдворению мигрантов, нарушивших режим пребывания в стране 2 .

В результате преобразований под руководством главы МВД Т. Мэй ужесточились требования для получения визы Tier2 для высококвалифицированных трудовых мигрантов ${ }^{3}$.

В этот период существенно снизился процент одобренных заявок на получение статуса беженца в Соедиёенном Королевстве. В 2015 г. во время кризиса с просителями убежища в Европе Великобритания отказалась принимать по квотам Брюсселя переселенцев с Ближнего Востока, которые уже находились в Европейском союзе. Взамен Д. Кэмерон дал обещание в течение пяти лет принять 20 тыс. сирийцев, которые находятся в лагерях непосредственно вблизи зоны конфликта ${ }^{4}$. Подобный жест умиротворил правозащитников и отвечал интересам безопасности государства (в страну попадут только те беженцы, которые пройдут проверку), однако не помог снизить нагрузку с континентальной Европы, столкнувшейся с беспрецедентным наплывом вынужденных переселенцев.

\section{Отношение этнических сообществ к членству в Европейском союзе}

По словам С. Джавид, сменившего Э. Радд на посту главы МВД, новая миграционная система Великобритании после выхода из ЕС будет более справедливой 5

По замыслу руководства Соединённого Королевства, количество трудовых мигрантов из Евросоюза после брекзита закономерно снизится, поскольку правительство не будет предоставлять им административных преференций ${ }^{6}$. В будущем, взяв за основу австралийскую модель привлечения квалифицированных трудовых мигрантов, кабинет планирует реформировать миграционное законодательство ${ }^{7}$.

Выступая перед конфедерацией британской промышленности в ноябре 2018 г., Т. Мэй заявила, что после брекзита граждане ЕС независимо от их компетенции и опыта не будут иметь преимуществ перед инженерами из Сиднея или разработчиками компьютерных программ из Дели 8 . Премьер-министр, очевидно, апеллировала к тем этническим сообществам Британии, которые голосовали за выход из $\mathrm{EC}^{9}$.

Дело в том, что «неблагоприятная среда» настроила некоторых выходцев из африканских и азиатских стран против Евросоюза, сделав их убеждёнными брекзитёрами. Большин-

apr/17/home-office-destroyed-windrush-landing-cards-says-ex-staffer (дата обращения: 15.12.2018).

${ }_{1}$ Commonwealth migrants arriving before 1971, year ending June 2017. URL: http://www.migrationobservatory. ox.ac.uk/commonwealth-migrants-arriving-1971-year-ending-june-2017/ (дата обращения: 15.12.2018).

2 Amber Rudd urged to resign over immigrant removal targets. URL: https://www.theguardian.com/politics/2018/ apr/26/amber-rudd-admits-home-office-set-local-targets-for-deportations (дата обращения: 15.12.2018).

The non-EU workers who'll be deported for earning less than $£ 35,000$.URL: https://www.theguardian.com/money/ 2016/mar/12/eu-workers-deported-earning-less-35000-employees-americans-australians (дата обращения: 15.12.2018).

${ }^{4}$ David Cameron promised to take in 20,000 Syrian refugees. What have the Tories actually delivered? URL: https:// www.independent.co.uk/news/uk/politics/syrian-refugee-crisis-refugees-british-government-20000-4000-progress-howmany-migrants-immigration-a7219971.html (дата обращения: 15.12.2018).

Sajid Javid plans «fairer, more compassionate» immigration system. URL: https://www.theguardian.com/uknews/2018/jun/06/sajid-javid-plans-fairer-more-compassionate-immigration-system (дата обращения 15.12.2018).

${ }^{6}$ EU migration to fall significantly after Brexit, as Sajid Javid defies Cabinet objections to unveil crackdown. URL: https://www.telegraph.co.uk/politics/2018/09/24/eu-migrants-fall-significantly-brexit-sajid-javid-defies-cabinet/?utm_ medium=Social\&utm_source=Facebook\#Echobox=1537822249 (дата обращения: 15.12.2018).

${ }^{7}$ Sajid Javid set to bring in Australian-style immigration model and SCRAP 100k target. URL: https://www.express. co.uk/news/uk/954249/Sajid-Javid-uk-immigration-plans-immigrant-targets (дата обращения: 15.12.2018).

${ }^{8}$ PM speech to CBI: 19 November 2018. Prime Minister Theresa May's speech to the Confederation of British Industry.URL: https://www.gov.uk/government/speeches/pm-speech-to-cbi-19-november-2018 (дата обращения: 15.12.2018).

9 Brexit will hit ethnic minorities harder. Why is this ignored? URL: https://www.theguardian.com/commentisfree/ 2018/nov/22/brexit-ethnic-minorities-hit-job-losses-poverty-eu (дата обращения: 15.12.2018). Научно-аналитический вестник ИЕ РАН, 2018, №6 
ство из них считали несправедливым, что мобильные граждане ЕС имели лёгкий доступ к рынку труда Соединённого Королевства ${ }^{1}$. Например, такие организации как «мусульмане для Британии» и «африканцы для Британии» открыто агитировали за брекзит, чтобы лишить мигрантов из Европейского союза их привилегированного положения.

Представители этнических групп полагают, что длительные исторические связи стран бывших колоний с Лондоном дают им право рассчитывать на ослабление миграционных требований. Логика их рассуждений заключается в следующем: поскольку население колоний сражалось на стороне Соединённого Королевства в годы Второй мировой войны, участвовало в восстановлении британской экономики в послевоенный период, то они вправе считать себя «в большей степени британцами, чем граждане ЕС». Однако на практике мигранты из стран Содружества не располагают миграционными привилегиями в отличие от мобильных граждан Евросоюза.

Некоторые выходцы из Азии и Африки голосовали за выход из Европейского союза в надежде, что брекзит приведёт к росту торгового оборота со странами их происхождения и будет содействовать еще большей иммиграции в Британию. Часть мигрантов считала, что общая сельскохозяйственная политика Евросоюза не позволяла Великобритании расширять торговлю в указанных секторах с африканскими и азиатскими рынками.

Однако среди этнических меньшинства была велика и доля сторонников ЕС. Мигранты-бремейнеры полагали, что антимиграционная кампания брекзитёров разжигает ненависть на национальной почве, а их призывы ограничить миграцию казались представителям этнических сообществ расистскими и ксенофобскими ${ }^{2}$.

\section{Будущий статус трудовых мигрантов из ЕС}

В 2017 г. 38\% эмигрантов в Соединённое Королевство - граждане Евросоюза, а около $50 \%$ - выходцы из третьих стран, т.е. лица, въезд которых подлежит иммиграционному контролю $^{3}$. В сентябре 2018 г. был опубликован отчёт Экспертной комиссии по миграции (ЭКМ) ${ }^{4}$, в котором отмечено положительное воздействие миграции из стран ЕС на ряд общественных сфер Британии 5 .

Речь шла в первую очередь о том, что высококвалифицированная рабочая сила из Евросоюза позитивно повлияла на производительность и инновации в Британии. Мобильные граждане ЕС также внесли существенный вклад в налоговые сборы. Одновре́менно с этим отмечено, что низкоквалифицированные рабочие Соединённого Королевства могли испытать негативный эффект от миграции в виде серьёзной конкуренции.

Правительство обещало принять во внимание рекомендации доклада при дальнейшей разработке миграционной стратегии постбрекзит. Главное предложение состоит в том, что к гражданам Европейского союза должны применяться такие же миграционные правила, как и к гражданам из третьих стран, если торговое соглашение между Лондоном и Брюсселем не

\footnotetext{
${ }^{1}$ Minority ethnic attitudes and the 2016 EU referendum. URL: http://ukandeu.ac.uk/minority-ethnic-attitudes-and-the2016-eu-referendum/ (дата обращения: 15.12.2018).

${ }^{2}$ Britain's eight million ethnic minorities are still being ignored over Brexit. URL: https://www.newstatesman.com/ politics/brexit/2018/09/britain-s-eight-million-ethnic-minorities-are-still-being-ignored-over (дата обращения: 15.12 . 2018).

${ }_{3}^{3}$ Migration Statistics. Briefing Paper. House of Commons Library. Number SN06077, 11 December 2018. P. 14.

4 Экспертная комиссия по вопросам миграции (Migration Advisory Committee) - независимая структура, которая оказывает консультации и предоставляет рекомендации правительству по вопросам миграции. См. подробнее: https://www.gov.uk/government/organisations/migration-advisory-committee.

${ }^{5}$ EEA migration in the UK: Final report. Migration Advisory Committee September 2018. URL: https://assets. publishing.service.gov.uk/government/uploads/system/uploads/attachment_data/file/741926/Final_EEA_report.PDF (дата обращения: 15.12.2018).
} 
будет содержать специальных статей по нормам движения рабочей силы.

Экспертная комиссия по миграции рекомендовала не создавать новый тип визы для трудовых мигрантов из ЕС, включая рабочих средних специальностей, а регулировать их въезд по визам Tier2. Полное закрытие границы для низкоквалифицированных рабочих из Евросоюза после брекзита авторы считают нецелесообразной и малоэффективной мерой.

Правительство пообещало, что статус 3,7 млн граждан $\mathrm{EC}^{1}$, которые проживают в Beликобритании не изменится.

19 декабря 2018 г. МВД Соединённого Королевства представило Белую книгу с новыми предложениями по миграционной политике страны². Отмечено, что после брекзита низкоквалифицированные работники из стран Европейского союза больше не смогут автоматически получать разрешение на работу в Британии. Для сезонных работников будут предусмотрены краткосрочные визы на срок до 12 месяцев. Однако по таким визам трудовые мигранты не смогут получать финансовую помощь от государства, будут лишены права ходатайствовать о получении вида на жительство и не смогут перевезти семью. В отношении квалифицированных работников, въезжающих по пятилетней визе Tier2, ежегодная квота (20700 специалистов) будет отменена. Отмечено, что правительство будет проводить дополнительные консультации, нужно ли оставить требование к минимальной зарплате в 30 тыс. ф.ст. в год для получения такой визы гражданами ЕС. Ожидается, что новые меры вступят в силу после завершения транзитного периода (с 2021 г.).

Очевидно, что ужесточение миграционных требований для граждан ЕС со стороны Лондона зеркально отразится и на статусе британских подданных в Евросоюзе.

\section{Выводы}

1. Дискуссии в Соединённом Королевстве о необходимости справедливой миграционной системы, которая не дискриминирует людей по происхождению, существенно обострились на фоне «скандала Виндраш» и окончательного формирования «неблагоприятной среды» для мигрантов, главным архитектором которой считают именно Т. Мэй. Усилия правительства по сокращению сальдо миграции не принесли должного результата. Ужесточение миграционной политики привело к росту недовольства со стороны этнических групп. Снижение численности граждан ЕС, в том числе и их выезд на Родину, связан в первую очередь с неопределённостью переговоров по брекзиту.

2. Премьер-министр пытается преподнести электорату соглашение о выходе из Евросоюза как возможность внедрить справедливую иммиграционную систему для ряда этнических меньшинств. Дискурс о недискриминационной системе миграции может привести к напряжённостям между гражданами ЕС и группами мигрантов из стран Содружества наций.

3. Тезис о вреде трудовой миграции из стран Евросоюза как главный аргумент брекзитёров не находит подтверждения среди экспертов. Отмечена польза высококвалифицированной трудовой миграции из ЕС. Правительство планирует, что с 2021 г. низкоквалифицированные работники из Европейского союза будут въезжать по краткосрочной трудовой визе, а высококвалифицированные рабочие - по визе Tier2. Ожидается, что иммиграция из стран ЕС в Британию существенно сократится.

\footnotetext{
${ }^{1}$ По состоянию на июнь 2018 г. в Великобритании проживает 3,7 млн граждан ЕС (не считая самих британцев, которые формально также относятся к гражданам Евросоюза). Исследования экономической деятельности мобильных граждан Евросоюза в Соединённом Королевстве показали, что 54\% работают по найму и имеют постоянного работодателя, а 10\% - самозаняты. См. Подробнее: Migration Statistics. Briefing Paper. House of Commons Library. Number SN06077, 11 December 2018. P. 27.

${ }^{2}$ Home Secretary announces new skills-based immigration system. URL: https://www.gov.uk/government/news/homesecretary-announces-new-skills-based-immigration-system (дата обращения: 20.12.2018).
}

Научно-аналитический вестник ИЕ РАН, 2018, №6 
4. Великобритания не может представить полноценную миграционную стратегию, в т.ч. в отношении граждан стран Содружества наций, пока не определены параметры «развода» с Европейским союзом.

\section{Список литературы}

Хахалкина Е.В. Иммиграционная политика Д. Кэмерона (2010-2015 гг.) // Современная Европа. 2015. №4. С. 47-58.

\section{References}

Hahalkina E.V. Immigracionnaya politika D. Kehmerona (2010-2015 gg.) // Sovremennaya Evropa. 2015. №4. S. 47-58.

EEA migration in the UK: Final report. Migration Advisory Committee September 2018. URL: https://assets.publishing.service.gov.uk/government/uploads/system/uploads/attachment_data/file/7 41926/Final_EEA_report.PDF.

EU migration to and from the UK. URL: https://migrationobservatory.ox.ac.uk/resources/briefings/eu-migration-to-and-from-the-uk/

Home Secretary announces new skills-based immigration system. URL: https://www.gov.uk/ government/news/home-secretary-announces-new-skills-based-immigration-system.

Immigration Act 2014. URL: https://www.gov.uk/government/collections/immigration-bill.

Immigration Act 2016. URL: https://www.gov.uk/government/collections/immigration-bill2015-16.

Immigration and asylum: changes made by the Coalition Government 2010-2015. URL: https://researchbriefings.parliament.uk/ResearchBriefing/Summary/SN05829\#fullreport.

State Intervention into Renting: Making sense of the impact of policy changes. URL: https://research.rla.org.uk/wp-content/uploads/state-intervention-into-renting-2017-report.pdf.

\section{The New Contours of UK Migration Policy}

Author. Kira Godovanyuk, Candidate of Sciences (Politics), Senior Research Associate at the UK Studies Center, Institute of Europe, Russian Academy of Sciences. Address: 11-3, Mokhovaya str., Moscow, Russia, 125009. E-mail: kira.godovanyuk@gmail.com.

Abstract: Since 2010 Conservative government of the United Kingdom has been delivering measures to tighten up the entry and stay rules for immigrants. «Hostile environment» for illegal migrants along with the anti-migration discourse targeting the EU citizens facilitated the victory of Leavers. Currently along with the disputes over terms of Brexit, the future migration policy including post-brexit status of the EU citizens is being debated. The contours of new migration policy are still unclear, although UK leadership made a point that the main focus will be done on skilled workers from the third countries.

Key words: UK, migration, «hostile environment», European Union, Brexit, Commonwealth, Theresa May, visa Tier2, foreign labour force.

DOI: http://dx.doi.org/10.15211/vestnikieran6201812 